\title{
On Founding Human Communication \& Technology
}

Jeffrey A. Hall

The University of Kansas

Well-timed opportunities feel like a gift. For me, the founding of Human Communication $\mathcal{E}$ Technology is one such moment.

My research has long straddled the intersection between interpersonal communication and computer-mediated communication. Yet, I was a latecomer to an important conversation about access to suitable publication outlets at that intersection. Scholars of communication and technology, many of whom came from interpersonal backgrounds, felt there was a growing demand for a new journal focused on technology housed in communication. Like me, they felt that often their best work in mobile and social media had to be taken to relationship journals where they were told they were too much technology focused, or to technology journals where their relationship approach or communication theories were less than warmly received.

At the same time that I became aware of this important discussion among my professional colleagues, I began to learn more about the open access initiatives at my home university, The University of Kansas. As part of its mission, KU's libraries hosts many open access journals across a range of disciplines as well as an open access hub called KU ScholarWorks. Thus, the critical infrastructure for manuscript submission and the peer review process could be supported by KU's libraries. This commitment to open access would allow any new journal to avoid the pay-to-publish schemes that are all too common across academia. Free and open access aligns with my own values about scholarship and the values of many of my peers who study technology. I found that with not a little bit of luck, there was an opportunity to bring these two issues together.

Although the study of human communication and technology spans several disciplines, including media psychology and computer science, communication has always been at the forefront of the study of new media. The International Communication Association has one excellent journal dedicated to such work (i.e., Journal of Computer-Mediated Communication) (JCMC), but no other journal in communication has such a focus. There are several prominent interdisciplinary journals focused on the study of technology (e.g., New Media $\mathcal{E}$ Society, Computers in Human Behavior). As a consequence of a lack of outlets, our best work had to be taken outside of our home discipline. I believe this contributes to the marginalization of communication as a place for the scholarly study of technology and communication.

As the Vice-Chair and Program Planner of the Human Communication and Technology Division at the National Communication Association (NCA) in 2018, I

CONTACT Jeffrey A. Hall hallj@ku.edu Department of Communication Studies, University of Kansas, Bailey Hall, 1440 Jayhawk Blvd., Rm 102, Lawrence, KS 66045-7574, USA 
had the platform and audience to discuss this new opportunity. The response was immediate and encouraging. After a few additional meetings with KU libraries and an energetic group of scholars across the country, I felt that the time had come to launch the journal by the time we met again in 2019 .

We formed a panel focused on this need for a new journal for the NCA conference in 2019. There, we discussed the importance and timeliness of the journal in both the context of current communication and technology research and the history of founding journals within and outside of the communication discipline. We discussed the journal's editorial aims and scope, and its long-term goals. And we discussed the central role that communication has played and will play in the future study of new media. The inaugural issue of Human Communication $\mathcal{E}$ Technology represents the ideas of many of the same scholars who led this discussion well before I was involved. Their essays, presented as a single issue, are available free and open to the public to serve as a record of the conception of the journal.

\section{Justification for Editorial Focus}

In my role as editor, the focus of the journal is on the intersection of relationships and technology (https://journals.ku.edu/hct/about). This focus reflects the interests of the journal's most ardent supporters. I expect the journal's direction will change with new leadership or if the scope proves too narrow. Here, I thought it would be appropriate to explain why I chose to focus the journal in the way I did.

I believe there is too much research on technology rather than on the people using it. A recent bibliometric analysis (Foote, Shaw, \& Hill, 2018) identified the 12 primary themes of 20,330 articles on social media, and not a single theme is focused on personal relationships. The most common theme (i.e., media use) has the key words "Facebook" and "people" but not friends or relationships. Of the 12 most common themes, there were zero themes using the words "relationships," friendship," "romantic," "personal," "conversation," or "social interaction" (Foote et al., 2018).

Another bibliometric analysis of research on online social networks published in the top scholarly journals in the past 20 years made this astonishing claim: articles dedicated to the study of the role of social network sites in interpersonal relationships "did not necessarily examine the social relationships mediated by those social technologies" (Fu \& Lai, in press, p. 12). In other words, articles on social media published in top journals did not recognize that relationships are the foundation upon which online social networks are built, not the other way around. Furthermore, this same analysis (Fu \& Lai, in press) found very little research on multi-modal relationships because research in new media tends to be very platform specific, rarely accounting for uses of various platforms and modalities.

This suggests in research on personal media, users' pre-existing relationships with communication partners are treated as ancillary or, worse, utterly irrelevant to studying the phenomenon. For example, researchers often prioritize measuring technology use in relation to outcomes like well-being, but rarely consider the pre-existing relationship between the people on the sending and receiving ends of messages. Without question, the sender and receiver of the message play some role in its effects. 
When researchers insufficiently attend to the relational context of personal media use, they are adopting a technology-focused approach. I hope this journal will help start a larger conversation about what a relationship-focused approach to personal media use could look like. I hope the research published in this journal can explore the ways each modality and its use can be understood by the ways that it nourishes or diminishes human relationships. I hope research published in this journal can help understand how communication shapes and is shaped by technology - from choice of modality and platform, to the content and goal of the message, and to the ways people bend and exploit technology's features and functions to serve their needs.

I hope this journal will establish a venue for publishing high quality, peer reviewed, theoretically robust, and methodologically rigorous research on human communication and technology. I believe it has the potential become a vital venue for research that will guide the future of this area of study.

\section{Long-term Goals}

One of the long-term goals of this journal is to gain the attention of our colleagues at NCA, specifically about the feasibility of getting a technology-focused journal under NCA umbrella. NCA has been slow to adopt new journals. Its newest journal, Communication \& Critical/Cultural Studies, was established in 2004. Prior to that the Journal of International $\mathcal{E}$ Intercultural Communication was established in 2000, but no new journals have been founded since. There has been a tremendous missed opportunity by NCA to have not taken a similar initiative as ICA in launching JCMC in 1995. Technology has long been a critical part of human communication, and even more so in the past 25 years.

I personally hope that NCA will become a supporter of open access and free online publishing in the future for all of its journals. I do not intend to support $\mathrm{Hu}$ man Communication $\mathcal{E}$ Technology come under its umbrella until there is an alignment of values on open access.

\section{Conclusion}

I am thankful for the service of our esteemed colleagues who have agreed to serve on our editorial board, and particularly grateful to Art Ramirez for his guidance and mentorship in launching this journal. I look forward to seeing our excellent work find a home in communication.

\section{References}

Foote, J., Shaw, A., \& Hill, B. M. (2018). A computational analysis of social media scholarship. In J. Burgess, A. Marwick, \& T. Poell (Eds.), The SAGE handbook of social media (pp. 111-134). Los Angeles, CA: Sage Publications.

$\mathrm{Fu}$, J. S., \& Lai, C-H. (in press). Mapping the intellectual structure and roots of online social networks 1997-2017: Challenges and opportunities for computer-mediated communication research. Journal of Computer-Mediated Communication. 